\title{
Formulation and Evaluation of Polyherbal Shampoo to Promote Hair Growth and Provide Antidandruff Action
}

\section{Gaurav Lodha}

Department of Pharmaceutics, Dr. Vithalrao Vikhe Patil Foundation's, College of Pharmacy, Vilad ghat, Ahmednagar, (MS), India-414111

\begin{abstract}
The assurance of therapy with minimal side effects has been proven that ayurvedic formulation is to be promising for cosmetic use too. Maintenance of other factor shall not fulfill the need so extraneous treatment is essential that to which is safe. In case of hair disorder like dandruff problem, proper selection of ayurvedic ingredient with their required amounts, dosage form can be formulated as powder shampoo to fight against dandruff. A more radical approach in reducing the synthetic ingredient is by incorporating natural extract whose functionality is comparable with their synthetic ingredient. A shampoo is a cleansing aid for the hair and is counted among the foremost beuty products. Several herbs are reported to be effecting is controlling such fungi in our laboratory an antidandruff herbal shampoo -Herbello was prepared and characterized. Certain improvements, especially with respect to viscosity, conditioning ability and antidandruff activity were nee ded. Most effective herbs were chosen and used in different combination for preparation of shampoo in order to improve antidandruff activity. This herbal shampoo was formulated using natural ingredient like Bhringraj (Eclipta Alba), Fenugreek(methi), Azadirachta indica (neem), Acacia concinna (shikakai), Sapindus mukorossi(reetha), Ocimum santum (tulsi), Piper betle (paan), Hhibiscus rosa sinensis (Gurhal), Camellia sinesis (green tea leaf), Citrus aurantifolia (lemon), Phyllanthus emblica (amla), Eclipta alba (Brhingaraj leaf powder), Aloe Vera (Aloe leaf Powder), Ashwagandha powder, Triphala powder Nagarmotha Powder, Brahmi Root. The formulation at laboratory scale was done and evaluated for number of parameters to ensure its safety, stability and efficacy.
\end{abstract}

Keywords: Hair Dandruff shampoo, cream shampoo, Herbal Material, Antidandruff shampoo.

Article Info: Received 14 July 2019; $\quad$ Review Completed 23 Aug 2019; $\quad$ Accepted 29 Aug 2019; Available online 30 Aug 2019

\section{Cite this article as:}

Lodha G, Formulation and Evaluation of Polyherbal Shampoo to Promote Hair Growth and Provide Antidandruff Action, Journal of Drug Delivery and Therapeutics. 2019; 9(4-A):296-300 http://dx.doi.org/10.22270/jddt.v9i4-A.3474

\section{*Address for Correspondence:}

Gaurav Lodha, Department of Pharmaceutics, Dr. Vithalrao Vikhe Patil Foundation's, College of Pharmacy, Vilad ghat, Ahmednagar, (MS), India-414111

\section{INTRODUCTION:-}

Dandruff, the excessive shedding of dead skin cell from scalp,is apparently caused by a fungus called Malassezia restricta and M. globosa. Malassezia formerly called pityrosporum is a yeast causing infection of skin and scalp (Shuster,1984).The replacement of cell on the scalp occur slowly and is not visible to the eye.The process of change is happening every month. If this there will be disruption on the scalp which we call dandruff. Herbal shampoos are the cosmetic preparations that with the use of tradition ayurvedic herbs are meant for cleansing the hair and scalp just like the regular shampoo.

Hair is an important part of human body to provide beauty. Innumerable instances from all the art forms can be cited supporting the special prominence accorded to hair by people of virtually all times and cultures. Little emphasis has been given in the cleaning of hairs. Now, washing hairs with shampoos has become common and practiced all around the world. Shampoos are widely used today based on synthetic ingredients or herbal ingredients. A shampoo is a preparation of surfactant in liquid, solid or powder, whichever is suitable. It removes grease, dirt and skin debris from the hair shaft and scalp without adversely affecting the user.

"Herbal shampoos are the cosmetic preparations that with the use of traditional ayurvedic herbs are meant for cleansing the hair and scalp just like the regular shampoo." They are used for removal of oils, dandruff, environmental pollution, etc.

\section{MATERIALS AND METHODS:-}

\section{Procurement of Material:-}

The different parts of the plantswere selected for the study having hair care property. The plants are methi powder, Neem leaf (Azadirachta indica), Shikakai fruit (Acacia concinna), Aloe leaf (Aloe Barbadensis), Henna Leaf (Lawsonia inermis), Brahmi root (Centella asiatica), Ritha 
fruit (Sapindus mukorossi), Amla fruit (Embelica officinalis ), Nagarmotha (Cyperus rotundus) and Tulsi. The powder od methi, Amla fruit, Neem leaf, Shikakai fruit, Aloe leaf, Henna Leaf, Ritha fruit were collected from the local market. The raw materials collected were given with their respective biological source and uses in 9table no.1) ingredients in the hair care; even they are responsible to provide the nutrition to the body. Herbs have long been associated with hair care and are often ingredients of conditioners, shampoos and rinses. The selection of active ingredients for hair care powder is often based on the ability of the ingredient to prevent damage to the skin as well as to improve the quality of the skin by way of cleansing, nourishing and protecting the skin. In the paper, we reported the development and evaluation of herbal hair care powder.

Table 1: Material used

\begin{tabular}{|l|l|l|l|l|}
\hline Sr. no. & Ingredient & Biological name & Quantity & Use of Ingredient \\
\hline 1 & Bhringraj Powder & Eclipta Alba Powder & $2.50 \mathrm{gm}$ & Hair Tonic \\
\hline 1 & Henna & Dried leaves powder & $1.25 \mathrm{gm}$ & Growth of Hairs and Conditioners. \\
\hline 2 & Lemon & Fresh juice form & $2.50 \mathrm{gm}$ & Hair Strength and Gives Vitamin C \\
\hline 3 & Amla & Dried ripe fruit powder & $2.50 \mathrm{gm}$ & $\begin{array}{l}\text { Darkening of Hairs and hair growth } \\
\text { promoters. }\end{array}$ \\
\hline 4 & Neem & $\begin{array}{l}\text { Fresh leaves/ dried leaves } \\
\text { powder }\end{array}$ & $1.25 \mathrm{gm}$ & $\begin{array}{l}\text { Fights scalp infections, prevents } \\
\text { dryness and dandruff. }\end{array}$ \\
\hline 5 & Aloevera leaf & Leaf freshly part in gel form & $2.50 \mathrm{gm}$ & Nourishment of hairs \\
\hline 6 & Methi powder & Dried seeds & $2.50 \mathrm{gm}$ & Conditioning and nourishment of hair. \\
\hline 7 & Ashwagandha Powder & Dried powder & $2.50 \mathrm{gm}$ & Controls Hairfall. Promotes hair health. \\
\hline 8 & Reetha & Dried fruit powder & $2.50 \mathrm{gm}$ & Foaming agent \\
\hline 9 & Brahmi Root & Dried root & $2.50 \mathrm{gm}$ & Supports hair growth. \\
\hline 10 & Paan Leaf & Fresh leaves & $2.50 \mathrm{gm}$ & Antibacterial \\
\hline 11 & Nagarmotha & Dried ripe fruits powder & $2.50 \mathrm{gm}$ & Scalp disorder. \\
\hline 12 & Tulsi & Fresh leaves & $2.50 \mathrm{gm}$ & Anti-Bacterial \\
\hline 13 & Hibiscus rosasinesis & Fresh flower & $2.50 \mathrm{gm}$ & Hair Growth and Enrichment \\
\hline 14 & Shikakai & Dried pods powder & $0.25 \mathrm{gm}$ & Foam base and antidandruff agent. \\
\hline 15 & Green Tea Leaves & Fresh leaves & $2.50 \mathrm{gm}$ & Hair Growth and Enrichment \\
\hline 16 & Triphala & Dried powder & $2.50 \mathrm{gm}$ & Nutrition to hairs \\
\hline 17 & Sodium Lauryl Sulphate & & $1 \mathrm{gm}$ & Foaming agent. \\
\hline 18 & Water & & Q.S. 25 ml & Vehicle \\
\hline & & Total Quantity & $25 \mathrm{ml}$. & \\
\hline
\end{tabular}

\section{Method of Preparation}

Various Steps are involved in the preparation, These are namely drying,weighting, size reduction, mixing and sieving.

Let us describe them :-

Drying: - All the required powder are dried and then grinded.

Weighting: - All the required powder for the formulation were accurately weighted.

Size Reduction: - The size reduction was done by mortar and pestle. Also Handd mixer was used for more rigid ingredients.

Mixing: - By using a mixer all the ingredients were properly mixed, thus creating a homogenous and fine powder

Seiving :- Seiving is also necessary step to eliminate coarse particles. Seive no 90 was used to get the required fine powder.

\section{Evaluation of the Herbal Shampoo:-}

Herbal shampoos are needed to be evaluated after their formulation. Evaluation parameters help us to know Efficacy and stability of formulation. Thus the evaluation parameters are described below

Organoleptic Evaluation:-

Organoleptic evaluation involves evaluation by the naked eye. It includes colour, odour, texture, etc. The observed characteristics were noted respectively.

\section{General Characteristics of Powder:-}

These characteristics include evaluation of those characteristics which affect the external properties of the formulation. These include angle of repose, bulk density, tapped density. These are necessary to check the flow properties of powders and also to know about particle size.

Angle of repose:-

Bulk density: - Mass of the powder / Volume of the powder

Tapped Density: - Weight of Powder / Tapped Volume of Powder

\section{c. Physiochemical Evaluation}

\section{1. $\mathrm{pH}$}

The $\mathrm{pH}$ is calculated using pen $\mathrm{pH}$ Meter. The $\mathrm{pH}$ was measured of $10 \%$ Shampoo solution in distilled water. 5 readings were taken and the mean of it was considered as the $\mathrm{pH}$ of shampoo solution.

\section{Washability}

Formulations were applied on the skin and then washed off to observe the ease and extent of washing of the formulations by water.

\section{Solubility}

Two $\mathrm{ml}$ of the shampoo is added to $100 \mathrm{ml}$ of water.The solution formed was well shaken and then heated to increase solubility. After 10 mins of heating the solution was cooled down and then the quantity of residue was noted. 


\section{Loss on Drying}

Two grams of herbal powderused in formulation was taken and kept in apetri dish which was dry. The petri dish was placed in a dessicator for 3 days over calcium chloride crystals. After 3 days, powder was weighted again to check loss on drying.

\section{Skin Irritation Test}

- $\quad$ Let the area of skin performing the test is washed, dry and clean.

- Apply a small amount of shampoo on the upper part of your inner arm (at the crook of the elbow).

- Cover it with a bandage.

- Choose a time of day where you can leave the patch test in place for least 24 hours without getting it wet.

- If you are sensitive to any of the ingredients, a reaction such as reddening, burning, itching, or other irritation, should occur within twenty-four hours of application.

- If you feel any irritation or reaction, remove the bandage immediately and wash area with soap and water.

- If you don't see or feel any reaction, the formulation is probably safe to use.

Eye irritation test:-

About $2 \%$ of shampoo solution was dripped into the eyes of albino rats. The eyes were held open with clips at the lid. The progressive damage to the eyes of rats at specific intervals at an average period of 5seconds. Observe if there are of swelling of eyelids, inflammation of iris, etc.

\section{Moisture content determination}

The powders utilized for the preparation of the shampoo were taken $15 \mathrm{gm}$ each and mixed well. Then they were heated on an hot air oven at a temperature of $110 \mathrm{oC}$. The weight loss was observed noted after a heating of about 20 minutes.

\section{Wetting Time}

Canvas paper was used to evaluate wetting time. Canvas paper disc of $1 \mathrm{~cm}$ inch diameter were cut into circles which was floated over the surface of the formulated shampoo solution. The time required for the disc to begin to sink was noted as the wetting time.

\section{Stability Study}

Stability study of the shampoo was done by keeping the shampoo in an air tight container at cool and dry place for 3 days. The shampoo was observed for changes in colour, texture, etc at intervals of $12 \mathrm{hrs}, 24 \mathrm{hrs}, 48 \mathrm{hrs}, 72$ hours

Nature of hair after washing:-

Nature of hairs after washing by the shampoo can be noted by the responses of the volunteers taken to test the shampoo on their hairs for about 3 hair washes.

Foaming Index

Two ml of shampoo was weighted accurately and transferred into $250 \mathrm{ml}$ conical flask containing $100 \mathrm{ml}$ of boiling water. Then it is warmed gently for 50 minutes, cooled and filtered and make up the volume to $100 \mathrm{ml}$ in standard volumetric flask. The obtained warm solution is taken in 10 test tubes in a series of successive portion of $1,2,3 \ldots 10 \mathrm{ml}$ and remaining volume is made up with water to $10 \mathrm{ml}$. Then the test tubes were shaken in longwise motion for 20 seconds at speed of 4 frequencies/ second. Then the test tubes are allowed to stand in the test tube for 20 minutes. The height of the foam was measured.

\section{RESULTS}

Table 2: Organoleptic evaluation:-

\begin{tabular}{|c|c|c|}
\hline Sr. No. & Test & Observation \\
\hline 1 & Colour & Dark brown \\
\hline 2 & Odour & Pleasant \\
\hline 3 & Texture & Smooth \\
\hline 4 & Taste & Bitter \\
\hline
\end{tabular}

Table 3: Powder Characteristics.

\begin{tabular}{|c|c|c|}
\hline Sr. no. & Test & Result \\
\hline 1 & Particle Size & $15-20 \mu \mathrm{m}$ \\
\hline 2 & Angle of repose & $3105{ }^{\prime \prime} \mathrm{C}$ \\
\hline 3 & Bulk density & $0.4577 \mathrm{~g} / \mathrm{cm}^{3}$ \\
\hline 4 & Tapped density & $0.617 \mathrm{~g} / \mathrm{cm} 3$ \\
\hline
\end{tabular}

Table 4: Foaming index of shampoo:-

\begin{tabular}{|l|l|l|l|l|l|l|l|l|l|}
\hline T1 & T2 & T3 & T4 & T5 & T6 & T7 & T8 & T9 & T10 \\
\hline 0.7 & 0.8 & 0.6 & 0.5 & 0.9 & 0.6 & 0.1 & 0.8 & 0.7 & \\
\hline
\end{tabular}

Note :- T1-T10 are test tube numbers

Foaming index $=1000 / \mathrm{a}=1000 / 7=142.85$

\section{Skin and Eye irritation Tests:-}

The skin irritation test was done as per mentioned procedure. The observations showed no redding or swelling of the skin. Also there were no itching sensations. The test was done at about 10 volunteers which were found totaaly healthy before and after the tests.
The eye irritation was done in 10 albino rats. There was no irritation, swelling of eyelids or ulceration and inflammation of iris observed in the albino rats. The rats were found to be absolutely healthy after the tests.

Thus the skin and eye irritation tests were proved to be successful. 

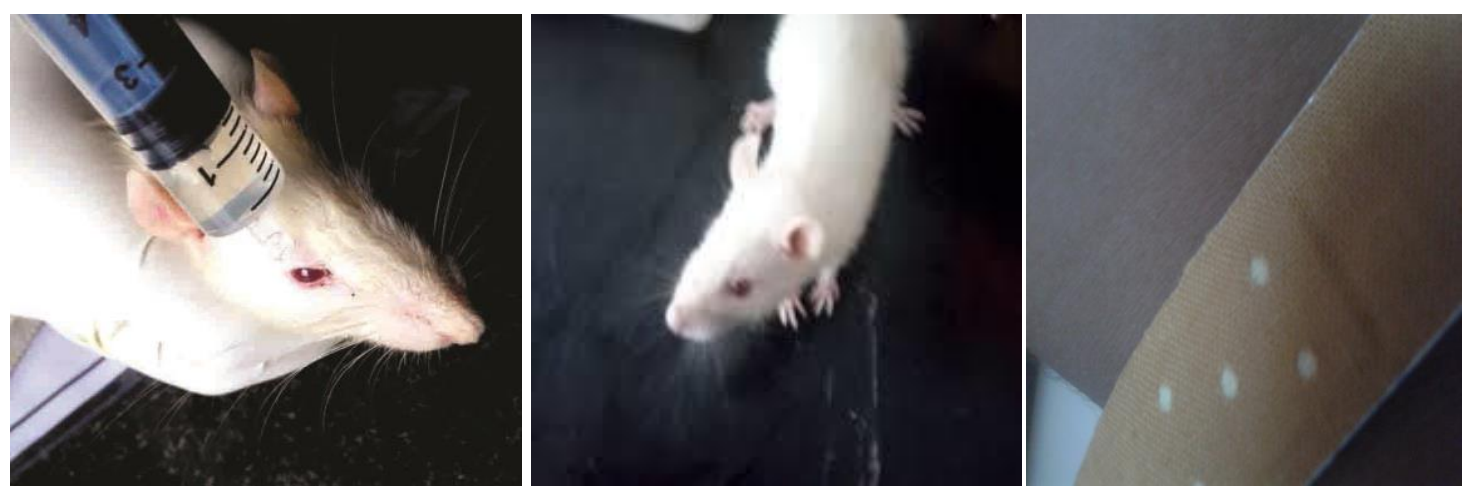

Table 5: Physiochemical Properties of Herbal Shampoo :-

\begin{tabular}{|l|l|l|}
\hline $\begin{array}{l}\text { Sr. } \\
\text { no. }\end{array}$ & Physiochemical Evaluation & Result \\
\hline 1 & $\mathrm{pH}$ & 5.47 \\
\hline 2 & Washability & Easily \& readily washable \\
\hline 3 & Solubility & Soluble in water \\
\hline 4 & Skin \& eye irritation & No harmful effects on skin and eyes \\
\hline 5 & Foaming capacity & Good foaming capacity \\
\hline 6 & Extractive values & \\
\cline { 2 - 3 } & Alcohol & $18 \% \mathrm{w} / \mathrm{w}$ \\
\cline { 2 - 3 } & Water & $14 \% \mathrm{w} / \mathrm{w}$ \\
\hline 7 & Ash value & \\
\cline { 2 - 3 } & Total ash content & $4.91 \% \mathrm{w} / \mathrm{w}$ \\
\cline { 2 - 3 } & Acid insoluble ash & $1.61 \% \mathrm{w} / \mathrm{w}$ \\
\hline 8 & Dirt dispersion & Moderate \\
\hline 9 & Moisture content determination & $5.07 \%$ \\
\hline 10 & Wetting time & $171+/-0.05$ \\
\hline 11 & Stability & Very Stable \\
\hline 12 & Nature of hair after washes & Soft and Silky \\
\hline
\end{tabular}

\section{DISCUSSION}

Medicinal plants used in the formulation of herbal shampoo were found as rich source of useful chemical components. Plants or parts of plants such as Bhringraj, Amla, Henna, Reetha, Neem, Tulsi, Shikakai, Ashwagandha, Brahmi, etc had been reported for hair growth, antidandruff, cleansing and conditioning. All the required quality control parameters were checked carefully. All the necessary evaluation parameters gave positive and acceptable results. The results obtained in this present study depicts that when these useful herbal ingredients are incorporated in shampoo gives more stable and effective product with good appearance and patient compliance. The $\mathrm{pH}$ of the shampoo is good which helps in improving and enhancing the qualities of hair, minimizing the irritation to the eyes and stabilizing the ecological balance of the scalp. The positive results obtained shows us that this formulation is stable and will be acceptable. S.L.S. provides efficient foam to the formulation in contact with water which helps in decreasing of surface tension and proper application of the shampoo on the scalp. The formulation has good wetting capacity and foaming index. All the evaluation parameters like Organoleptic evaluation, General powder Characters, Physicochemical Evaluation, Cleaning action, foaming, Dirt dispersion, Wetting agent, Nature of hair after wash was carried out under standard guidelines and was found to be within the standard range. Skin irritation and eye irritation tests yielded successful results.

\section{CONCLUSION}

A survey of global hair care market trends indicates that consumer use of herbal products has significant increased over the past years. The factors like UV radiations, use of harsh chemical products have direct and indirect impact on the hair. To overcome this problems the present study has the best undertaken to design a herbal shampoo which will not only give hair protection but also give conditioning effect, antidandruff effect, cleansing action, shine and manageability. The present study emphasizes on the potential of herbal extracts and powders for cosmetic purposes. Hence we conclude that the formulation of polyherbal shampoo is effective in reducing dandruff without irritation, enables hair growth, hair smoothning, less side effects and better conditioning effect. Present investigations was done to formulate the herbal shampoo based upon traditional knowledge and to develop few parameters for quality, stability and purity of herbal shampoo The awareness and need for cosmetics with herbs is on demand at present due to their lesser side effects and low costs. Hence the Formulation and evaluation of polyherbal antidandruff Shampoo is stable and effective.

\section{CONFLICT OF INTERESTS}

Declared none. 


\section{REFERENCES}

1. Harrison JL, Davis KD. Cold-evoked pain varies with skin type and cooling rate: a psychophysical study in humans Pain., 1999; 83: 123-135.

2. Maderson PF. Mammalian skin evolution: a reevaluation. Exp Dermatol., 2003; 12: 233-236.

3. Randall VA, Botchkareva NV. The biology of hair growth. In: Ahluwalia GS, ed. Cosmetic Application of Laser and Light-Based System. Norwich, NY: William Andrew Inc., 2009: 3-35.

4. Randall VA. Is alopecia areata an autoimmune disease? Lancet., 2001; 358: 1922-1924.

5. Maffei C, Fossati A, Rinaldi F, et al. Personality disorders and psychopathologic symptoms in patients with androgenetic alopecia. Arch Dermatol., 1994; 130: 868872.

6. Wolfram LJ. Human hair: a unique physicochemical composite. J Am Acad Dermatol., 2003; 48: S106- S114.

7. Pooja A, Arun N, Maninder K. Shampoos based on synthetic ingredients vis-a-vis shampoos based on herbal ingredients: a Review. Int J Pharm Sci Rev Res 2011;7(1):41e6.
8. Potluri A, Asma SSK, Rallapally N, Durrivel S, Harish GA. Review on herbs used in Anti-dandruff shampoo and its evaluation parameters. Indo Am J Pharm Res 2013;3(4):3266e78.

9. Sarath C, Vipin KV, Ann RA, Lindumol KV, Arun S. Development and evaluation of antidandruff shampoo based on natural sources. J Pharm Phytother 2013;1(4):10e4.

10. Shinde PR, Tatiya AU, Surana SJ. Formulation development and evaluation of herbal antidandruff shampoo. Int J Res Cosmet Sci 2013;3(2):25e33.

11. Srivasuki KP. Nutritional and health care benefits of amla. J Pharmacogn 2012;3(2):147e51.

12. Tarun J, Susan J, Susan VJ, Criton S. Evaluation of pH of bathing soaps and shampoos for skin and hair care. Indian J Dermatol 2014;59(5):442e4.

13. Formulation, evaluation and comparison of the herbal shampoo with the commercial shampoos* Khaloud Al Badi, Shah A. Khan* Department of Pharmacy, Oman Medical College, Muscat, Omanbeni-suef university j ournal of basic and applied sciences 3 (2014) 301 e305 